\title{
A preliminary study on identifying specific risk factors of post-partum depression
}

\author{
Afiya M. Shafi' ${ }^{1}$, Rohit Jain ${ }^{2 *}$, Smita Pandey ${ }^{3}$ \\ ${ }^{1}$ M. Phil Student, Institute of Behavioural Science, Gujarat Forensic Sciences University, Gandhinagar, Gujarat, India \\ ${ }^{2}$ Department of Obstetrics and Gynaecology, GMERS Medical College, Gandhinagar, Gujarat, India \\ ${ }^{3}$ Institute of Behavioural Science, Gujarat Forensic Sciences University, Gandhinagar, Gujarat, India
}

Received: 22 November 2019

Accepted: 28 November 2019

*Correspondence:

Dr. Rohit Jain,

E-mail: docrohitjain270378@gmail.com

Copyright: (c) the author(s), publisher and licensee Medip Academy. This is an open-access article distributed under the terms of the Creative Commons Attribution Non-Commercial License, which permits unrestricted non-commercial use, distribution, and reproduction in any medium, provided the original work is properly cited.

\begin{abstract}
Background: Pregnancy and childbirth are important events in the life of a woman and also highly vulnerable period of various physiological and psychological illnesses. Several literatures propound that $22 \%$ young Indian mothers are showing depressive symptoms after delivery. The consequence of maternal depression is adverse both for mother and development of the child. Objective of this study was to examine the social and obstetric factors contributing postpartum depression.

Methods: Women, 18-35 years of age, having four days to one-year postpartum period was taken from the tertiary care hospital settings. Terminal illness, still birth delivery and comorbid psychiatric illness was excluded. Screening and diagnosis of postpartum depression done based on international classification of diseases (ICD 10) using Edinburgh post-natal depression scale (EPDS). A comparative approach by the means of descriptive statistics was implied for data analysis where mothers with depressive symptoms are experimental group and non-depressed mothers were acted as the controls.

Results: Study findings indicated a statistically significant association between postpartum depression and risk factors such as occupation and average social economic class, first time delivery.

Conclusions: It is a preliminary study in a restricted geographical area, not covering the neurobiological risk factors of postpartum depression. Hence, the future study will focus on the large sample size in a multi areal population for assuring the accuracy of the result.
\end{abstract}

Keywords: Demographic factors, Obstetric factors, Post-partum depression, Risk factors, Social factors

\section{INTRODUCTION}

The time period of pregnancy and postpartum is associated with immense feeling of happiness and positive expectation but also the time of additional pressure and difficulties for the new parents. During the period of Pregnancy and delivery, both mother and father have to deal with various biopsychosocial changes. Consequently, "pregnancy and the post-partum are times of increased vulnerability for the onset or relapse of a mental illness". ${ }^{1}$ Mild to moderate psychiatric disturbances can takes place during pregnancy and postpartum and most common disorders are depression and anxiety. ${ }^{2}$ At the time of childbirth women become susceptible to get mentally ill that may cause problems of affective disorders in postpartum states. ${ }^{3}$ A considerable advancement has occurred in clinical researches specific to the domain of perinatal mental illness, its prevalence, 
the risk factors and the consequences to the mother, foetus and infant, since then. A great number of government faculties and professional organizations have stated the procedures for the early indication and prevention of perinatal mental illness, along with the increased focus on clinical and professional scrutiny. Along with this additional focus on the financial aspect of these conditions have reduced a great amount of distress on the lives of women, their children and families suffering from these mental illnesses. ${ }^{4}$

Meta analytic study showed that post-partum depression (PPD) is the most common complication of childbearing, occurring in $10-15 \%$ of women after delivery. ${ }^{5}$ The onset time period is indicated to be within the first four weeks postpartum and most cases require vital assistance of mental health professional. Screening for postnatal mood disturbance can be difficult given the number of somatic symptoms typically associated with having a new baby that are also symptoms of major depression, for example, sleep and appetite disturbance, diminished libido, and low energy. While very severe postpartum depressions are easily detected, less severe presentations of depressive illness can be easily dismissed as normal or natural consequences of childbirth can be considered as the major disadvantage in diagnosing the illness. ${ }^{6}$

Perinatal mental illnesses are prevalent during pregnancy and as long as 1 year after delivery which is categorized as part of psychiatric disorders. The postpartum timeframe is debatable: most investigators use a period ranging from 4 weeks after delivery to 3 months after delivery. ${ }^{7,8}$ Perinatal mental illness is an umbrella term under which the following disorders ranging from mild depression and anxiety, mania, to florid psychosis can be categorized. Additionally, it can be considered as perinatal mental illness in which disorders that were present during consumption, or emerge during pregnancy or in the postpartum period. Among disorders that emerge in the postpartum period, some emerge soon after childbirth, and others emerge later or more variably. ${ }^{9}$

There are two main classification systems used within psychiatry: The American Psychiatric Association's Diagnostic and Statistical Manual of Mental Disorders now in its fourth edition (DSM-V, 2013) and the $10^{\text {th }}$ edition of the International Classification of Diseases, (ICD-10), published by the World Health Organization. ${ }^{10,11}$ DSM-V (2013) defined postpartum depression are major depressive episode which occur with a peripartum onset. This specifier can be applied to the current or, if full criteria are not currently met for a major depressive episode, most recent episode of major depression if onset of mood symptoms occurs during pregnancy or in the 4 weeks following delivery (DSM V, 2013). It also states that mood episodes can have their onset either during pregnancy or postpartum. ${ }^{10}$ However, the World Health Organization and the Centers for Disease Control and Prevention expand this duration to include pregnancy and up to 1 year postpartum and other groups use this broader definition to be more inclusive. . $^{5,13}$

Researchers and clinicians have strived to bring out the influencing factors of postpartum depression and maternal health. Causes of PPD may be physiological, social, psychological or multifactorial. ${ }^{14}$ Based on the random effects model, the overall pooled estimate of the prevalence of postpartum depression in Indian mothers was $22 \% .{ }^{15}$ India's reproductive health programs do not include services for prevention or treatment of PPD. Furthermore, there is currently no screening tool designed for use in clinical practice for the early identification of perinatal women with postpartum depression. The growing number of incidents and prevalence rate of maternal psychiatric illness showing a need for greater care of mother's mental health for the sake of healthy motherhood and better nurturing and development of young generation in India. ${ }^{15}$ This study was attempt to explore the social and obstetric factors which contribute for postpartum depression in Indian women and a comparative frame to understand strategy of maternal wellbeing.

\section{METHODS}

This study was attempted to examine the factors recognized to be relevant in the onset of postpartum depression in Indian women and a comparative frame to understand strategy of maternal wellbeing. A crosssectional, prospective, observational, non-interventional survey was conducted in department of obstetrics and gynaecology, GMERS Medical College, Gandhinagar, Gujarat between July 2016 to January 2017. The study was approved by institutional ethics committee. Written informed consent was obtained from parents of children before enrolling them into the study.

Purposive sampling was used and females in the age group of 18-35 years who were having four days to oneyear postpartum period were include in the study as a representative sample population. The women, who had a stillbirth or belonging to specific population, such as mothers living with human immunodeficiency virus or having any other terminal illness were excluded from the study. A total number of 110 samples were taken. The survey was divided into two groups on the basis of screening. One group was having subject with depressive symptoms and the other group was having healthy females. The design was a matched control design. Diagnosis of depression were executed by using Edinburgh Postnatal Depression Scale (EPDS), which is developed on the basis of International Classification of Diseases (ICD 10) diagnostic criteria for PPD. ${ }^{11}$ Women were then divided into two groups according to their EPDS score; women with score of 11 and above were classified as having depression symptoms, while women with score lower than 11 were classified as not having depression symptoms. Non-depressed mothers were acted as the controls for correlating various risk factors. 
Presence of depression was taken as the dependent variable and risk factors were assessed as the independent variable.

Demographic data was used to collect the age group, educational qualification, occupation, domicile, social economic status and family type. Obstetric details including the information of number of deliveries, number of children, date of last delivery and type of delivery. Edinburgh postnatal depression scale (EPDS) was used to screen the postpartum depression symptoms. ${ }^{16}$ The scale was developed in Scotland at health centers in Livingston and Edinburgh (UK) by Cox, Holden and Sagovsky in $1987 .{ }^{16}$ A 10-item self-report instrument will be used to assess depressive symptomatology. Items were rated on a 4-point scale to produce a summative score ranging from 0 to 30 , with 10 or higher than 10 scores indicating lower maternal mood. This instrument is the most frequently used instrument to assess postpartum depressive symptomatology and to identify at-risk mothers. The assessment scale was converted into local language such as Hindi and Gujarati and will be standardized by retranslated to original language.

Measurement of mental health and risk factors were assessed by five parameters - presence of depression symptoms, attitude towards motherhood, personality factors, major life events and psychosocial health during the gestational and postpartum period. Data was collected from both rural and urban population, in the hospital setting. Collection of data included the briefing of the intention of the study, research purpose, filling of a consent form in local language (Hindi and Gujarati). Participants were selected strictly by voluntary participation, with an ethical clause of confidentiality. Required information regarding the inclusion and exclusion criteria was also explicitly explained and subject were selected accordingly. Scales of measurement and assessment of tools were explained in details.

\section{Statistical analysis}

The data did not have missing elements and all of the 110 subjects interviewed were taken into the data pool. Data were analyzed using SPSS (version 16, SPSS) to obtain descriptive and inferential statistics. Descriptive statistics were used to identify the characteristics of the sample. Mann- Whitney test was used to detect the differences in socio-demographics characteristics and psycho social variables between women who had symptoms of depression and those who did not. Significance level was set to be $\mathrm{P}<0.05$.

\section{RESULTS}

Out 110 populations of post-natal women $70 \%$ of mothers are between to 18-28 years age group and $30 \%$ of them are between 28-35 years age group. $57.3 \%$ women are completed their high school education were
$25.5 \%$ are graduates and $17.3 \%$ are post graduates. Majority of subjects were $(77 \%)$ unemployed or homemakers, $7.3 \%$ are engaged in daily wages work (manual Labour), $13.6 \%$ were employed in clerical post and $9.1 \%$ were occupied in officer post both in private and government sector. $41.8 \%$ women belonged from below average socio-economic class, $39.1 \%$ belonged from middle-class socio-economic class and $19.1 \%$ were belonged from upper-class socio-economic background. $51.8 \%$ of subjected were living in nuclear family and 48.2 of them are living in joint family. $56.4 \%$ of women living in urban area and $43.6 \%$ of women living in rural areas (Table 1).

Table 1: Socio-demographic characteristics of subjects $(\mathbf{N}=\mathbf{1 1 0})$.

\begin{tabular}{|c|c|c|c|}
\hline Variables & & Frequency & $\%$ \\
\hline \multirow{2}{*}{$\begin{array}{l}\text { Age } \\
\text { (years) }\end{array}$} & $18-28$ & 77 & 70.0 \\
\hline & $28-35$ & 33 & 30.0 \\
\hline \multirow{3}{*}{ Education } & High school & 63 & 57.3 \\
\hline & Graduate & 28 & 25.5 \\
\hline & Post graduate & 19 & 17.3 \\
\hline \multirow{3}{*}{ Occupation } & Unemployed & 77 & 70.0 \\
\hline & Daily wages & 8 & 7.3 \\
\hline & Clerical/ officer & 25 & 22.7 \\
\hline \multirow{3}{*}{$\begin{array}{l}\text { Socio- } \\
\text { Economic } \\
\text { Status }\end{array}$} & Below average & 46 & 41.8 \\
\hline & Average & 43 & 39.1 \\
\hline & Above average & 21 & 19.1 \\
\hline \multirow{2}{*}{ Family type } & Nuclear & 57 & 51.8 \\
\hline & Joint & 53 & 48.2 \\
\hline \multirow{2}{*}{ Domicile } & Urban & 62 & 56.4 \\
\hline & Rural & 48 & 43.6 \\
\hline
\end{tabular}

Table 2: Obstetrics characteristics of subjects $(\mathbf{N}=\mathbf{1 1 0})$.

\begin{tabular}{|llll|}
\hline Variables & & Frequency & $\%$ \\
\hline \multirow{2}{*}{$\begin{array}{l}\text { Number of } \\
\text { delivery }\end{array}$} & First & 60 & 54.5 \\
\cline { 2 - 4 } & Second & 42 & 38.2 \\
\cline { 2 - 4 } & Third & 8 & 7.3 \\
\hline \multirow{3}{*}{$\begin{array}{l}\text { Post-partum } \\
\text { trimester }\end{array}$} & One week & 31 & 28.2 \\
\cline { 2 - 4 } & 3 months & 25 & 22.7 \\
\hline History of abortion/ & 6 months & 38 & 34.5 \\
\cline { 2 - 4 } miscarriage & 9 months & 16 & 14.5 \\
\hline \multirow{2}{*}{ Type of delivery } & No & 21 & 19.1 \\
\cline { 2 - 4 } & Normal & 68 & 80.9 \\
\cline { 2 - 4 } & LSCS & 42 & 61.8 \\
\hline
\end{tabular}

In the present sample $54.5 \%$ of women were primiparous (given birth to first child), $38.2 \%$ women were given birth to second child and $7.3 \%$ of women given birth to her third child. $28.2 \%$ women were having postpartum at one week, $22.7 \%$ of women were having 3 months of antenatal period, $34.5 \%$ of women were having 6 months of antenatal period and $14.5 \%$ of women were having 9 months of antenatal period. $19.1 \%$ of women reported 
previous history of abortion and miscarriage were $80.9 \%$ were reported no history of abortion or miscarriage. $61.8 \%$ women had normal delivery were $38.2 \%$ women given birth by lower segment caesarean section (LSCS) (Table 2).

In total, 110 new post-natal cases participated in the study. Out of total 110 women, 30 (27.3\%) were diagnosed with depression EPDS in the study (Figure 1).

On comparing the socio-demographic factors among women with depression and women without depression, females with PPD were significantly more likely to be working women $(\mathrm{P}<0.001)$ and belonged to average socio-economic class $(\mathrm{P}<0.004)$ (Table 3$)$.

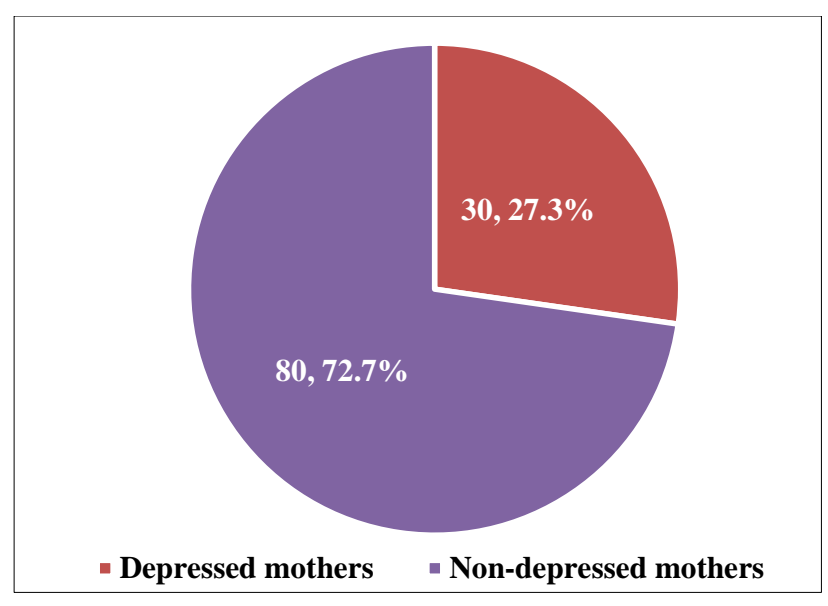

Figure 1: Prevalence of post-partum depression among subjects $(\mathbf{N}=\mathbf{1 1 0})$.

Table 3: Mean difference, odd ratio of demographic variables between depressed and non-depressed mothers.

\begin{tabular}{|c|c|c|c|c|c|c|}
\hline Variables & & $\begin{array}{l}\text { With depression } \\
(\mathbf{N}=\mathbf{3 0})\end{array}$ & $\begin{array}{l}\text { Without depression } \\
(\mathbf{N}=\mathbf{8 0})\end{array}$ & $\begin{array}{l}\text { Odd } \\
\text { ratio }\end{array}$ & $\begin{array}{l}\text { Chi } \\
\text { square/ Fisher }\end{array}$ & P-value \\
\hline \multirow{2}{*}{ Age (years) } & $18-28$ & $24(80.0 \%)$ & $53(66.2 \%)$ & \multirow{2}{*}{$\begin{array}{l}2.03 \\
(0.77-5.58)\end{array}$} & \multirow{2}{*}{1.96} & \multirow{2}{*}{0.161} \\
\hline & $28-35$ & $6(20.0 \%)$ & $27(33.8 \%)$ & & & \\
\hline \multirow{3}{*}{ Education } & High school & $19(63.3 \%)$ & $44(55.0 \%)$ & \multirow{3}{*}{-} & \multirow{3}{*}{0.961} & \multirow{3}{*}{0.763} \\
\hline & Graduate & $4(13.3 \%)$ & $24(30 \%)$ & & & \\
\hline & Post graduate & $7(23.3 \%)$ & $12(15.0 \%)$ & & & \\
\hline \multirow{3}{*}{ Occupation } & Unemployed & $14(46.6 \%)$ & $63(78.8 \%)$ & \multirow{3}{*}{-} & \multirow{3}{*}{10.702} & \multirow{3}{*}{$0.001^{*}$} \\
\hline & Daily wages & $0(0 \%)$ & $8(10.0 \%)$ & & & \\
\hline & Clerical/officer & $16(53.4 \%)$ & $9(11.2 \%)$ & & & \\
\hline \multirow{3}{*}{$\begin{array}{l}\text { Socio- } \\
\text { economic } \\
\text { status }\end{array}$} & Below average & $6(20.0 \%)$ & $40(50.0 \%)$ & \multirow{3}{*}{-} & \multirow{3}{*}{8.211} & \multirow{3}{*}{$0.004 *$} \\
\hline & Average & $15(50.0)$ & $28(35.0 \%)$ & & & \\
\hline & Above average & $9(30.0 \%)$ & $12(15.0 \%)$ & & & \\
\hline \multirow{2}{*}{ Family type } & Nuclear & $20(66.7 \%)$ & $37(46.2 \%)$ & \multirow{2}{*}{$\begin{array}{l}2.32 \\
(0.967-5.58)\end{array}$} & \multirow{2}{*}{3.610} & \multirow{2}{*}{0.057} \\
\hline & Joint & $10(33.3 \%)$ & $43(53.8 \%)$ & & & \\
\hline \multirow{2}{*}{ Domicile } & Urban & $17(56.7 \%)$ & $45(56.2 \%)$ & \multirow{2}{*}{$\begin{array}{l}1.017 \\
(0.43-2.37)\end{array}$} & \multirow{2}{*}{0.002} & \multirow{2}{*}{0.969} \\
\hline & Rural & $13(43.3 \%)$ & $35(43.8 \%)$ & & & \\
\hline
\end{tabular}

$* \mathrm{P}<0.05$ : statistical significance difference.

Table 4: Mean difference, odd ratio of obstetric variables among depressed and non-depressed mothers.

\begin{tabular}{|c|c|c|c|c|c|c|}
\hline Variables & & $\begin{array}{l}\text { With depression } \\
(\mathbf{N}=\mathbf{3 0})\end{array}$ & $\begin{array}{l}\text { Without depression } \\
(\mathbf{N}=\mathbf{8 0})\end{array}$ & $\begin{array}{l}\text { Odd } \\
\text { ratio }\end{array}$ & $\begin{array}{l}\text { Chi } \\
\text { square/ Fisher }\end{array}$ & P-value \\
\hline \multirow{3}{*}{$\begin{array}{l}\text { Number of } \\
\text { delivery }\end{array}$} & First & $25(83.3 \%)$ & $35(43.8 \%)$ & \multirow{3}{*}{-} & \multirow{3}{*}{14.633} & \multirow{3}{*}{$* 0.000$} \\
\hline & Second & $5(16.7 \%)$ & $37(46.2 \%)$ & & & \\
\hline & Third & $0(.0 \%)$ & $8(10.0 \%)$ & & & \\
\hline \multirow{4}{*}{$\begin{array}{l}\text { Post-partum } \\
\text { trimester }\end{array}$} & One week & $11(36.7 \%)$ & $20(25.0 \%)$ & & \multirow{4}{*}{2.898} & \multirow{4}{*}{0.089} \\
\hline & 3 months & $6(20.0 \%)$ & $19(23.8 \%)$ & & & \\
\hline & 6 months & $13(43 \%)$ & $25(31.2 \%)$ & - & & \\
\hline & 9 months & $0(0 \%)$ & $16(20.0 \%)$ & & & \\
\hline \multirow{2}{*}{$\begin{array}{l}\text { History of abortion } \\
\text { /miscarriage }\end{array}$} & Yes & $5(16.7 \%)$ & $16(20.0 \%)$ & \multirow{2}{*}{$\begin{array}{l}0.800 \\
(0.265-2.41)\end{array}$} & \multirow{2}{*}{1.56} & \multirow{2}{*}{0.693} \\
\hline & No & $25(83.3)$ & $64(80.0 \%)$ & & & \\
\hline \multirow{2}{*}{$\begin{array}{l}\text { Type of } \\
\text { delivery }\end{array}$} & Normal & $16(53.3 \%)$ & $52(65.0 \%)$ & \multirow{2}{*}{$\begin{array}{l}0.615 \\
(0.263-1.44)\end{array}$} & \multirow{2}{*}{1.247} & \multirow{2}{*}{0.264} \\
\hline & LSCS & $14(11.5 \%)$ & $28(35.0 \%)$ & & & \\
\hline
\end{tabular}

$* \mathrm{P}<0.05$ : statistical significance difference. 
Table 5: Significance difference in means across scales of EPDS between depressed and non-depressed mothers.

\begin{tabular}{|lllll|}
\hline Variables & $\begin{array}{l}\text { Depressed }(\mathbf{N}=\mathbf{3 0}) \\
\text { Mean }\end{array}$ & Mean & Zepressed $(\mathbf{N}=\mathbf{8 0})$ & Palue \\
\hline EPDS 1 & 85.50 & 44.25 & -6.71 & $0.000^{*}$ \\
\hline EPDS 2 & 78.80 & 46.76 & -5.93 & $0.000^{*}$ \\
\hline EPDS 3 & 30.48 & 64.88 & -5.72 & $0.000^{*}$ \\
\hline EPDS 4 & 90.10 & 42.52 & -7.26 & $0.000^{*}$ \\
\hline EPDS5 & 31.10 & 64.65 & -5.47 & $0.000^{*}$ \\
\hline EPDS6 & 38.63 & 61.82 & -3.83 & $0.000^{*}$ \\
\hline EPDS7 & 19.08 & 69.16 & -8.04 & $0.000^{*}$ \\
\hline EPDS8 & 31.07 & 64.66 & -5.15 & $0.000^{*}$ \\
\hline EPDS9 & 26.25 & 66.47 & -6.69 & $0.000^{*}$ \\
\hline EPDS10 & 39.30 & 61.58 & -4.76 & $0.000^{*}$ \\
\hline
\end{tabular}

* P < 0.05: statistical significance difference.

Comparison of the obstetric factors among women with PPD and without it showed that depression was significantly associated with having only one child (primiparous). However, factors such as post-partum trimester, history of abortion and miscarriage and mode of delivery, did not affect the mental health of the participating women (Table 4).

On EPDS mean scores of item 1 (inability of being happy) 2 (inability in enjoyment) and 4 (anxiety and worry) are significantly greater in depressed group than the non-depressed $(\mathrm{P}=0.000)$. Mean score of items 3 (self-blaming), 5 (fear and panic), 6 (inability in coping), 7 (difficulty in sleeping), 8 (feeling of sadness), 9 (unhappy and crying), 10 (self-harming thoughts) are lesser in non-depressed mothers than depressed mothers and significant difference was found among depressed and non-depressed mothers $(\mathrm{p}=0.000)$ (Table 5).

\section{DISCUSSION}

The prevalence of PPD in the women was $27 \%$ in the study sample consistent with rates found in other studies with little variation in the South Asian region. ${ }^{17-20}$ While the participants in this study were diverse in relation to socioeconomic and educational levels, this study is limited by no proportion of ethnic minorities and single women. The high prevalence rate of depression may be because of the sampling method used in this study in which subjects were purposefully taken from psychiatric department also. The cut-off points on screening tools can be influenced the rate of depression. ${ }^{21}$

The main aim of the study was to identify the various risk factors for post-partum depression by examining set of relevant variables relating to socio-demographic, and obstetric factors in women while they were pregnant and after they had given birth. The descriptive analysis of socio- demographic variables in this study, depressed group shows significant difference with occupation and economic status. Females with PPD were more likely to be working women $(\mathrm{P}=0.001)$ and belonged to average socio-economic class $(\mathrm{P}=0.004)$. Out of 30 depressed women, 16 of them (53\%) developed mild to severe depressive symptoms after delivery. The findings were contradicted with previous literature findings reporting unemployment to be a significant contributor to PPD. ${ }^{22,23}$ The unusual finding in this study can be explain in terms of the double effort of a working woman taking in her daily life and poor working conditions. Most of the working women require managing both her household chores and work-related demands. Travelling in public transport, lack of public latrines, work set up which did not provide an inclusive atmosphere for mother who lactates can cause persistent stress during pregnancy and postpartum period eventually leads to depression. Selix and Goyal reported in their meta-analysis review that working mothers are faced with unique challenges because most return to work after 6 weeks (in private sector) of maternity leave or sooner based on financial circumstances. ${ }^{24}$ Demand from workplace, particularly shift work and stressful work environments, and cause many new mothers at an increased risk for PPD. ${ }^{25}$

Even though they are not experiencing poverty, people who are belonging to middle class family often face financial difficulties. This study observed that most of the time mothers from middle class family forced to seek maternal care from private hospitals rather than government hospitals because of the public perception that it is not suitable for their social status. This often leads to extra financial burden to woman's family with several other financial difficulties. Also, they are less likely to get financial benefits from government for hospital expenditure when compared with people belonging from below poverty line. This tendency to set their standards up to the society's expectations could be the reason of stress and depressive symptoms of postpartum mothers from middle class family.

In the current study depressed group did not show any statistical significance with age, education, place of 
residence and family type which supporting the findings of Saldanha et al. ${ }^{26}$ Out of 63 women reported having no higher education, 19 of them was found to be depressed, and out of 48 women belonging from rural area, 17 of them reported to be depressed which contradicts studies conducted in developing countries reporting low education level and rural background to be a significant contributor to PPD. ${ }^{17,27}$ The reason could be that these women enjoyed good social support as well as support of the spouse despite being less educated or belonging from rural area. Since pregnancy and child birth considered to be a gift, women get special care and attention from their family. They often get excuse from household chores and get more acceptances in her husband's family as she continuing their legacy. Karmaliani et al, concluding similar findings in her study conducted in Pakistan those local cultural influences may encourage their families to be more supportive and caring towards pregnant women, thus moderating mood disorders. ${ }^{28}$ Alternatively, because pregnancy is considered as an experience of celebration in Pakistan, women may inhibit negative feelings and experiences because an unborn child is considered a gift of nature.

Decreased rate of PPD among graduates and postgraduates noted in the study could be because of their higher self-esteem and better interpersonal relationship. Women from urban area are having more independent life and better life style choices, could be act as a protective factor from mood disturbances during pregnancy.

There was a statistically significant association found between parity and onset of PPD $(\mathrm{P}=0.000)$. A total number of 30 mothers with depression, 25 of them were given birth for first time $(83 \%)$, which consistent with previous studies that women at their first pregnancy (primigravida) were more likely to suffer from depression. ${ }^{28,29}$ For newly mothers sudden life changes and increased responsibility associated with child birth and child rearing could be a first time experiences. Failure in effective coping with these changes and responsibilities could eventually leads to depression.

Other obstetric factors such as post-partum complications, mode of delivery, history of abortion/ miscarriage did not affect the onset of depression in postpartum mothers which consistent with previous study findings. ${ }^{17,30} 5 / 30(16.7 \%)$ mothers who developed PPD had a history of abortions whereas 16/80 (20\%) in nondepressed mothers gave a history of abortions. This finding may be attributed to improved and better health facilities and safer procedures performed in the tertiary care hospital. Total number of 42 mothers in our study, underwent lower segment caesarean section (LSCS) and 68 had a normal delivery. Emergency caesarean has been reported to be a significant contributor to PPD. ${ }^{31}$ In this study, as mothers were prior informed, most of them were prepared for caesarean well in advance.
This study provides useful information about the prevalence of PPD and risk factors especially the role of socio-cultural environment and practices. This study showed that there are differences between pregnant women who had depression symptoms and pregnant women who did not have depression symptoms in relation to some socio demographic variables (Occupation and average social economic class), and obstetric factors such as first-time delivery. However, this study did not find differences between depressed and non-depressed women in relation to other socio demographic variables (age, education, place of residence, type of family), obstetric factors such as complications and history of abortion and type of delivery which have been associated with antenatal depression in other literature.

Since it is a preliminary study, the small sample size will be taken from a restricted area (Gandhinagar) which might be a limitation of this study. The study has not taken into account the role of biological factors along with other factors that were the focus of attention in this study.

A longitudinal study with large sample size in various geographical areas along with the follow up of obstetrician would elicit more predictors of post-partum depression. Hence community-based survey and prospective studies are better designs for these situations. Further researches with a large sample size in a multi areal population would provide a scope of developing a psychological assessment tool for measuring mental health and wellbeing of mothers from the early trimester of pregnancy to one year of postnatal period.

\section{CONCLUSION}

The results of this study suggest that antenatal service providers should routinely screen women for depression and anxiety during pregnancy, just as they routinely screen for other risk factors of potential harm to mothers and infants, with referral offered to appropriate services. Intervening early may stop progression of maternal mental illness and improve maternal and child outcomes. Given the limited health resources in developing countries like India, the study results could be used to target interventions to groups that are likely to be at greatest risk for depression during pregnancy and require closer monitoring. Maternal and child health policies must integrate maternal depression as a disorder of public health significance especially in developing countries. Early screening of the women may reduce the adverse outcomes among both mother and child. Proper counselling should be done to all the pregnant women and the family members for the birth preparedness.

Funding: No funding sources

Conflict of interest: None declared

Ethical approval: The study was approved by the Institutional Ethics Committee 


\section{REFERENCES}

1. Smith MV, Shao L, Howell H, Lin H, Yonkers KA. Perinatal depression and birth outcomes in a Healthy Start project. Matern Child Health J. 2011;15(3):4019.

2. Alipour Z, Lamyian M, Hajizadeh E. Anxiety and fear of childbirth as predictors of postnatal depression in nulliparous women. Women Birth. 2012;25(3):e37-43.

3. Stocky A, Lynch J. Acute psychiatric disturbance in pregnancy and the puerperium. Baillieres Best Pract Res Clin Obstet Gynaecol. 2000;14:73-87.

4. Beyond Blue. Clinical practice guidelines for depression and related disorders: anxiety, bipolar disorder, and puerperal psychosis in the perinatal period. A Guideline for Primary Care Health Professionals. Melbourne: The National Depression Initiative; 2011. Available at: https://cope.org.au/wpcontent/uploads/2013/12/Perinatal-Mental-HealthClinical-Practice-Guidelines.pdf. Accessed on $28^{\text {th }}$ May 2017.

5. O'Hara, MW, Swain AM. Rates and risk of postpartum depression - a meta-analysis. Int Rev Psychiatry. 1996;8(1):37-54.

6. Nonacs R, Cohen LS. Postpartum mood disorders: diagnosis and treatment guidelines. J Clin Psychiatry. 1998;59(Suppl 2):34-40.

7. Kendell RE, Chalmers JC, Platz C. Epidemiology of puerperal psychoses. Br J Psychiatry. 1987;150:66273.

8. Miller LJ. Postpartum depression. JAMA. 2002;287(6):762-5.

9. Brockington IF, Cernik KF, Schofield EM, Downing AR, Francis AF, Keelan C. Puerperal psychosis. phenomena and diagnosis. Arch Gen Psychiatry. 1981;38(7):829-33.

10. American psychiatric association. Diagnostic and statistical manual of mental disorders. 5th ed. Arlington: American Psychiatric Association; 2013.

11. World Health Organization. The ICD-10 classification of mental and behavioural disorders: clinical descriptions and diagnostic guidelines. Geneva: World Health Organization; 1992.

12. Wisner KL, Parry BL, Piontek CM. Clinical practice. Postpartum depression. N Engl J Med. 2002;347(3):194-9.

13. The World Health Report 2001. Mental Health: New Understanding, New Hope. Available at: https://www.who.int/whr/2001/en/whr01_en.pdf. Accessed on $28^{\text {th }}$ May 2017.

14. Fisher J, Tran T, Duc Tran T, Dwyer T, Nguyen T, Casey GJ, et al. Prevalence and risk factors for symptoms of common mental disorders in early and late pregnancy in Vietnamese women: a prospective population-based study. J Affect Disord. 2013;146(2):213-9.

15. Upadhyay RP, Chowdhury R, Aslyeh S, Sarkar K, Singh SK, Sinha B, et al. Postpartum depression in
India: a systematic review and meta-analysis. Bull World Health Organ. 2017;95(10):706-717C.

16. Cox JL, Holden JM, Sagovsky R. Detection of postnatal depression. Development of the 10-item Edinburgh postnatal depression scale. $\mathrm{Br} \quad \mathrm{J}$ Psychiatry. 1987; 150:782-6.

17. Patel V, Rodrigues M, De Souza N. Gender, poverty and post-natal depression: a cohort study from Goa, India. Am J Psychiatry. 2002;159:43-7.

18. Prabhu TR, Asokam TV, Rajeshwari A. Post-partum psychiatric illnesses. J Obstet Gynecol India. 2005;55(4):329-32.

19. Rahman A, Iqbal Z, Harrington R. Life events, social support and depression in childbirth: perspectives from a rural community in the developing world. Psychol Med. 2003;33:1161-7.

20. Sood M, Sood AK. Depression in pregnancy and postpartum period Indian. J Psychiatry. 2003;45(1):48-51.

21. Klainin P, Arthur DG. Postpartum depression in Asian cultures: A literature review. Int J Nurs Stud. 2009;46:1355-73.

22. Bödecs T, Szilágyi E, Cholnoky P, Sándor J, Gonda $\mathrm{X}$, Rihmer $\mathrm{Z}$, et al. Prevalence and psychosocial background of anxiety and depression emerging during the first trimester of pregnancy: data from a Hungarian population-based sample. Psychiatr Danub. 2013;25(4):352-8.

23. Dibaba Y, Fantahun M, Hindin MJ. The association of unwanted pregnancy and social support with depressive symptoms in pregnancy: evidence from rural Southwestern Ethiopia. BMC Pregnancy Childbirth. 2013;13:135.

24. Selix NW, Goyal D. Postpartum Depression Among Working Women: A Call for Practice and Policy Change. The J Nurse Pract. 2015;11(9):897-902.

25. Goyal D, Gay C, Lee K. Fragmented maternal sleep is more strongly correlated with depressive symptoms than infant temperament at three months postpartum. Arch Womens Ment Health. 2009;12(4):229-237.

26. Saldanha D, Rathi N, Bal H, Chaudhari B. Incidence and evaluation of factors contributing towards postpartum depression. Med JDY Patil Univ. 2014;7(3):309-16.

27. Chandran M, Tharyan P, Muliyil J, Abraham S. Postpartum depression in a cohort of women from a rural area of Tamil Nadu, India. Incidence and risk factors. Br J Psychiatry. 2002;181:499-504.

28. Karmaliani R, Asad N, Bann CM, Moss N, McClure EM, Pasha O, et al. Prevalence of anxiety, depression and associated factors among pregnant women of Hyderabad, Pakistan. Int J Soc Psychiatry. 2009;55:414-24.

29. Raisanen S, Lehto SM, Nielsen HS, Gissler M, Kramer MR, Heinonen S. Risk factors for and perinatal outcomes of major depression during pregnancy: a population-based analysis during 20022010 in Finland. BMJ Open. 2014;4:e004883. 
30. Johnstone SJ, Boyce PM, Hickey AR, Morris-Yatees AD, Harris MG. Obstetric risk factors for postnatal depression in urban and rural community samples. Aust New Zealand J Psychiatry. 2001;35:69-74.

31. Pfost KS, Stevens MJ, Lum CU. The relationship of demographic variables, antepartum depression, and stress to postpartum depression. J Clin Psychol. 1990;46:588-92.

Cite this article as: Shafi AM, Jain R, Pandey S. A preliminary study on identifying specific risk factors of post-partum depression. Int J Reprod Contracept Obstet Gynecol 2020;9:48-55. 